\title{
The 2-minute walk test is not a valid method to determine aerobic capacity in persons with Multiple Sclerosis
}

\author{
Heleen Beckerman ${ }^{\mathrm{a}, *}$, Martin Heine ${ }^{\mathrm{a}, \mathrm{b}}$, Lizanne E. van den Akker ${ }^{\mathrm{a}}$ and Vincent de Groot $^{\mathrm{a}}$ \\ ${ }^{a}$ Department of Rehabilitation Medicine, Amsterdam University Medical Centers, Vrije Universiteit, \\ MS Center Amsterdam, Amsterdam Public Health Research Institute, Amsterdam, The Netherlands \\ ${ }^{\mathrm{b}}$ Brain Center Rudolf Magnus and Center of Excellence for Rehabilitation Medicine, \\ University Medical Center Utrecht and Rehabilitation Center De Hoogstraat, Utrecht, The Netherlands
}

\begin{abstract}
.
BACKGROUND: Walking tests, like the 2-minute fast walk test, are simple, inexpensive performance-based tests, and therefore seem attractive to estimate the aerobic fitness in people with chronic diseases.

OBJECTIVE: To determine the criterion validity of the 2-minute fast walk test for estimating aerobic capacity in patients with Multiple Sclerosis (MS), by comparing it with the peak oxygen uptake (VO2peak in $\mathrm{mL} / \mathrm{kg} / \mathrm{min}$ ) as measured by Cardiopulmonary Exercise Testing (CPET) on a cycle ergometer.

METHODS: The 2 min fast walk test was performed on a marked indoor trajectory, using a static start protocol. Aerobic capacity (VO2peak, in $\mathrm{mL} / \mathrm{kg} / \mathrm{min}$ ) was derived from CPET on a cycle ergometer. Criterion validity was tested by means of Pearson's correlation coefficient and should be at least 0.70 for a good criterion validity of the 2 min walk test. Linear regression analysis was applied to more precisely estimate VO2peak.

RESULTS: In total 141 people with severe MS-related fatigue (mean age 47.0 years (range 23-68 years), 73\% women, median disease duration 7.8 years (range $0.3-28.7$ years)) performed both tests. The distance walked in two minutes ranged from 52.0 to $290.0 \mathrm{~m}$ (mean $175.1 \mathrm{~m}$, sd $44.9 \mathrm{~m}$ ), while the VO2peak varied between 11.31 and $40.28 \mathrm{~mL} / \mathrm{kg} / \mathrm{min}(\mathrm{mean}$ $22.52 \mathrm{~mL} / \mathrm{kg} / \mathrm{min}$, sd $6.07 \mathrm{~mL} / \mathrm{kg} / \mathrm{min}$ ). The correlation between the $2 \mathrm{~min}$ walk test and VO2peak was 0.441 (95\% CI: 0.309-0.570). The absolute residual error in estimated VO2peak was $5.47 \mathrm{~mL} / \mathrm{kg} / \mathrm{min}$.
\end{abstract}

CONCLUSIONS: Due to the poor correlation found between the 2 min walk test and VO2peak, the 2-min walk test cannot be recommended as a valid alternative for estimating aerobic capacity in persons with MS.

Keywords: Exercise capacity, Multiple Sclerosis, 2 minute walk test, criterion validity

\section{Introduction}

Cardiopulmonary exercise testing (CPET) using ergometry (e.g. cycling, treadmill walking, row-

\footnotetext{
*Address for correspondence: Heleen Beckerman, Department of Rehabilitation Medicine, Amsterdam University Medical Centers, Vrije Universiteit, MS Center Amsterdam, Amsterdam Public Health Research Institute, P.O. Box 7057, 1007 MB Amsterdam, The Netherlands. Tel.: +31 20 4440762; E-mail: h.beckerman@amsterdamumc.nl.
}

ing, stepping) combined with gas exchange analysis is considered the most common, valid and reliable method for the assessment of aerobic capacity in healthy people and people with medical conditions (Thompson, Gordon, \& Pescatello, 2010; Valet, Lejeune, Hakizimana, \& Stoquart, 2017). Maximal oxygen uptake (VO2max), the main outcome parameter of CPET, is accepted as the criterion measure or gold standard of aerobic capacity. However, laboratory-based fitness tests require expensive 
and cumbersome equipment and do require trained staff with specialized knowledge, resulting in limited availability in daily clinical practice. Walking tests, like the 2-minute fast walk test, are simple, inexpensive performance-based tests, that might be a good proxy measure for aerobic fitness (Valet et al., 2017).

Fixed time walk tests measuring the distance walked over extended periods of time (e.g. $6 \mathrm{~min}$ walk test) are widely used to characterize a patient's functional endurance and submaximal aerobic fitness in medical research and clinical practice (Cahalin, Mathier, Semigran, Dec, \& DiSalvo, 1996; ERS Task Force, Palange, Ward, Carlsen, Casaburi, Gallagher, Gosselink, O'Donnell, Puente-Maestu, Schols, Singh, \& Whipp, 2007; Mandic, Walker, Stevens, Nye, Body, Barclay, \& Williams, 2013). Indeed, these tests were originally directed at patients with cardiovascular or lung diseases, but have since been more broadly applied (Solway, Brooks, Lacasse, \& Thomas 2001; Mayorga-Vega, Bocanegra-Parrilla, Ornelas, \& Viciana, 2016; Marzolini, Oh, Corbett, Dooks, Calouro, MacIntosh, Goodman, \& Brooks, 2016). In patients with Multiple Sclerosis (MS), timed walk tests are most commonly applied to quantify walking performance (Gijbels, Dalgas, Romberg, de Groot, Bethoux, Vaney, Gebara, Medina, Maamâgi, Rasova, de Noordhout, Knuts, \& Feys, 2012). In addition, some authors recommend to use walk tests as submaximal aerobic tests or socalled field exercise tests to estimate the exercise tolerance (i.e. aerobic fitness) of people with MS (Valet et al., 2017; Mayorga-Vega et al., 2016; Paul, Coote, Crosbie, Dixon, Hale, Holloway, McCrone, Miller, Saxton, Sincock, \& White, 2014; LangeskovChristensen, Heine, Kwakkel, \& Dalgas, 2015).

In severely fatigued patients with MS, it was hypothesized that a low level of aerobic fitness might be an important target for treatment intervention, or a mediating factor in explaining therapy effects. Therefore, the aerobic capacity of participants of the TReating FAtigue in MS (TREFAMS-ACE) research programme, with three randomized clinical trials on Aerobic training, Cognitive Behavioural Therapy, and Energy Conservation Management respectively, was assessed at fixed time points during the oneyear follow-up (Heine, Verschuren, Hoogervorst, van Munster, Hacking, Visser-Meily, Twisk, Beckerman, de Groot, Kwakkel; \& TREFAMS-ACE study group, 2017; van den Akker, Beckerman, Collette, Twisk, Bleijenberg, Dekker, Knoop, de Groot; \& TREFAMS-ACE Study Group, 2017).
The objective of the study described in this paper was to determine the criterion validity of the $2 \mathrm{~min}$ walk test as a less resource-intensive alternative to CPET for testing the aerobic capacity of people with MS.

\section{Methods}

\subsection{Participants}

In this study, cross-sectional baseline data of two randomized clinical trials (RCTs), i.e. TREFAMSAerobic Training and TREFAMS-Cognitive Behavioural Therapy, were used (Heine et al., 2017, van den Akker et al., 2017). Participants who completed both the CPET and the 2 min walk test were included in the analyses. Inclusion criteria of the RCTs were; diagnosed with MS and severe fatigue indicated by a score of $\geq 35$ on the fatigue domain of the Checklist Individual Strength (CIS20r); ambulatory status (i.e., Expanded Disability Status Scale (EDSS) score <6); no diagnosis of depression (i.e., Hospital Anxiety and Depression Scale score $<11$ ); no initiation or change to pharmacologic treatment for fatigue during the previous 3 months; and aged 18 to 70 years. The study was approved by the Medical Ethics Committee of the VU University Medical Center, Amsterdam, The Netherlands (approval number 2010/289), and conducted according to the World Medical Association Declaration of Helsinki. Informed consent was signed by all participants prior to their participation.

\subsection{Cardiorespiratory exercise testing}

To evaluate aerobic capacity, participants performed a CPET including gas exchange measurement on a calibrated electromagnetic bicycle ergometer (Corival, Lode, Groningen, the Netherlands). The gas exchange of each participant was measured using breath-by-breath analysis (Quark CPET, COSMED, Rome, Italy). VO2peak was defined as the highest recorded $30 \mathrm{~s}$ mean during the final $2 \mathrm{~min}$ of exercise, and was expressed in $\mathrm{mL} / \mathrm{kg} / \mathrm{min}$ (Balady, Arena, Sietsema, Myers, Coke, Fletcher, ... .\& Interdisciplinary Council on Quality of Care and Outcomes Research, 2010; Heine, van den Akker, Verschuren, Visser-Meily, Kwakkel, \& TREFAMS-ACE Study Group, 2015; Driehuis, van den Akker, de Groot, Beckerman, 2018). In the exercise physiology literature, the terms $\mathrm{VO} 2$ max and $\mathrm{VO} 2$ peak are sometimes 
used interchangeably (Langeskov-Christensen et al., 2015). For clarity of this article, we prefer VO2peak, i.e. the peak value the individual has achieved during the exercise test. The most common primary criterion for attainment of maximum aerobic capacity in adults is a VO2 plateau despite a further increase in work rate. However, as only one-third of healthy persons are able to reach a VO2 plateau, secondary criteria are often added (Langeskov-Christensen et al., 2015). Therefore, the respiratory exchange ratio (RER) was also measured; this is the ratio of $\mathrm{CO} 2$ produced and $\mathrm{O} 2$ consumed in 1 breath, and increases with workload. Heart rate (HR) was measured continuously with a heart rate monitor (COSMED, S.r.l, Rome, Italy). Measurements commenced in a sitting position at rest for $3 \mathrm{~min}$, after which the participant performed a 3 min warm-up by cycling at $\geq 60 \mathrm{rpm}$ with a workload of 25 Watts (W). After the warm-up, the workload progressively increased each minute by $10 \mathrm{~W}$ for women and $15 \mathrm{~W}$ for men. Participants continued to cycle at a cadence of $\geq 60 \mathrm{rpm}$ throughout the test. The exercise test was terminated due to volitional exhaustion, a cadence $<45 \mathrm{rpm}$ or for safety reasons; stopping criteria compliant with the American College of Sports Medicine guidelines for clinical exercise testing (Thompson et al., 2010). At the end of the CPET, participants were asked to rate their perceived exertion on the validated Borg Scale, which rates from 6 ("no exertion at all") to 20 ("maximal exertion"). The secondary maximal exercise criteria are met at a perceived exertion $\geq 17$ on the Borg scale, an RER $>1.10$, or an HR within $90 \%$ of calculated maximal HR (220 - age, in years) (Balady et al., 2010; Heine et al., 2015; Driehuis et al., 2018, Langeskov-Christensen et al., 2015).

\subsection{The 2 min walk test}

In each study centre, the 2 min walk test was performed on marked indoor trajectories of 30 or $32 \mathrm{~m}$, using the same static start protocol. Participants were allowed to use walking aids and devices during the test as they would when walking outdoors. They were instructed to walk as fast as possible (brisk walking without running) for 2 minutes. When 1 minute had elapsed, they were told "You are doing well; you have 1 minute left". The distance covered after 2 min was documented.

Demographic and disease characteristics included were gender, age, body height $(\mathrm{cm})$, body weight $(\mathrm{kg})$, time since diagnosis and type of MS (classified as relapsing-remitting, primary progressive, or sec- ondary progressive). Disease severity was determined by a neurologist or rehabilitation physician using the Expanded Disability Status Scale (EDSS) (Kurtzke, 1983).

\subsection{Statistical analyses}

The strength of the relation between the 2 min fast walk test and VO2peak was analysed by means of Pearson's correlation coefficient, and should be at least be 0.70 for a good criterion validity of the $2 \mathrm{~min}$ walk test (Terwee, Bot, de Boer, van der Windt, Knol, Dekker, Bouter, \& de Vet, 2007; Pin, 2014).

An univariate regression analysis was used to estimate the predicted VO2peak from the 2 min walk test, the percentage of explained variance in $\mathrm{VO} 2$ peak, and the standard error of estimate between the predicted VO2peak and the measured VO2peak. A BlandAltman plot illustrates the mean differences between the measured VO2peak and the VO2peak predicted from the 2 min walk test distance (m) and $95 \%$ limits of agreement (Bland \& Altman, 1986).

To estimate VO2peak more precisely from the 2 min walk test, a multiple linear regression model was developed, including the independent variables age, gender, type of MS, EDSS, body height $(\mathrm{cm})$. Variables were included in the final model if they made a significant independent contribution $(P<0.05)$ to the explained variance in measured VO2peak. The added contribution of each variable to the prediction of VO2peak was expressed as partial correlation (partial R), that is the correlation that remains between $\mathrm{VO} 2$ peak and the independent variables after removing the correlation that is due to their mutual association with the other independent variables. All statistical analyses were performed using IBM SPSS Statistics for Windows, version 22.0. The linear regression models were checked for any violations of the assumptions of normality, linearity, and equality of variances.

\section{Results}

\subsection{Participants}

VO2peak and 2 min walk distance were available from 80 TREFAMS-Aerobic Training participants and 61 TREFAMS-Cognitive Behavioural Therapy participants. Enrolment occurred between October 2011 and December 2014. The mean age of the 141 participants was 47.0 years (range 23-68 years), 73\% 
were women. The median disease duration was 7.8 years (range $0.3-28.7$ years), with a median EDSS score of 3.0 (range 0.0-6.0). With regard to the type of MS, $78.3 \%$ participants had a relapsing remitting MS, whereas the others had a progressive type of MS.

\subsection{The 2 min walk test and CPET}

Overall, the distance participants walked in two minutes ranged from 52.0 to $290.0 \mathrm{~m}$ (mean $175.1 \mathrm{~m}$, sd $44.9 \mathrm{~m}$ ), while VO2peak varied between 11.31 and $40.28 \mathrm{~mL} / \mathrm{kg} / \mathrm{min}$ (mean $22.52 \mathrm{~mL} / \mathrm{kg} / \mathrm{min}$, sd $6.07 \mathrm{~mL} / \mathrm{kg} / \mathrm{min}$ ). The cardiorespiratory fitness in men was significantly higher than in women (mean difference $4.17 \mathrm{~mL} / \mathrm{kg} / \mathrm{min}$, 95\% CI: $1.99-6.35$ ). However, the distance walked in 2 minutes did not significantly differ between men and women (mean difference $11.6 \mathrm{~m}$; 95\% CI:-5.2 to 28.4).

The Pearson's correlation coefficient of the $2 \mathrm{~min}$ walk test distance and measured VO2peak was 0.441 (95\% CI: 0.309-0.570), and smaller than the 0.70 criterion (Fig. 1). The $2 \mathrm{~min}$ walk test distance explained $19.5 \%$ of the variance in VO2peak. The absolute residual error in estimated VO2peak was $5.47 \mathrm{~mL} / \mathrm{kg} / \mathrm{min}$. Fig. 2 and Fig. 3 (i.e. the Bland and Altman plot with -9.82 to $13.47 \mathrm{~mL} / \mathrm{kg} / \mathrm{min}$ as limits of agreement) further illustrate the consequences of inaccurate estimation of VO2peak; in patients with a high VO2peak, the 2 min fast walk test underestimates their VO2peak, and in patients with a low VO2peak the VO2peak is overestimated by using the distance of the 2 min fast walk test. The correlation between the average $\mathrm{VO} 2$ peak (on the $\times$ axis in the Bland and Altman plot) and the difference between

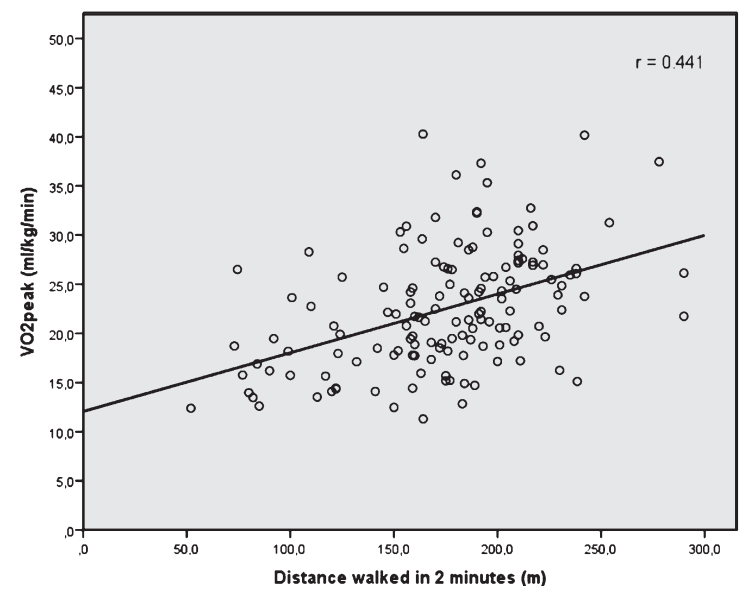

Fig. 1. Scatterplot with correlation line between 2 min walk test distance (in meters) and the measured VO2peak (in $\mathrm{mL} / \mathrm{kg} / \mathrm{min}$ ).

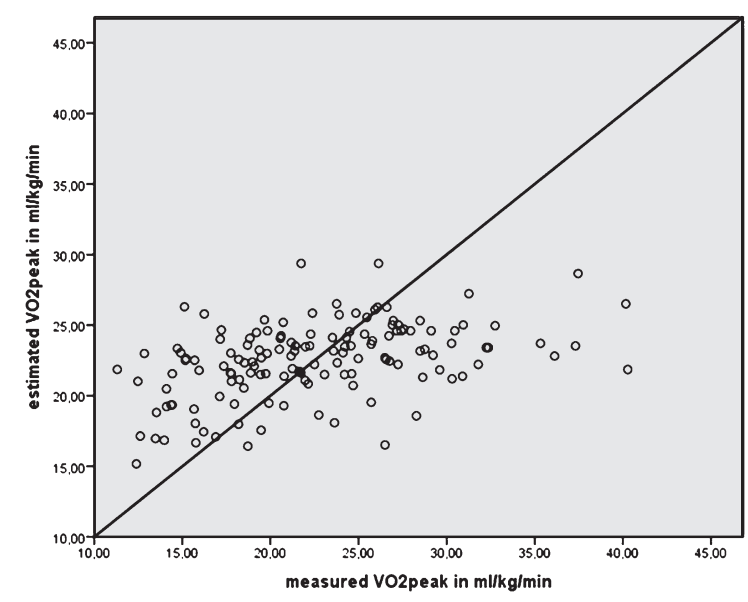

Fig. 2. Plot of measured VO2peak in $\mathrm{mL} / \mathrm{kg} / \mathrm{min}$ by VO2peak estimated from 2 min walk test distance in meters. The diagonal line represents the line of perfect agreement.

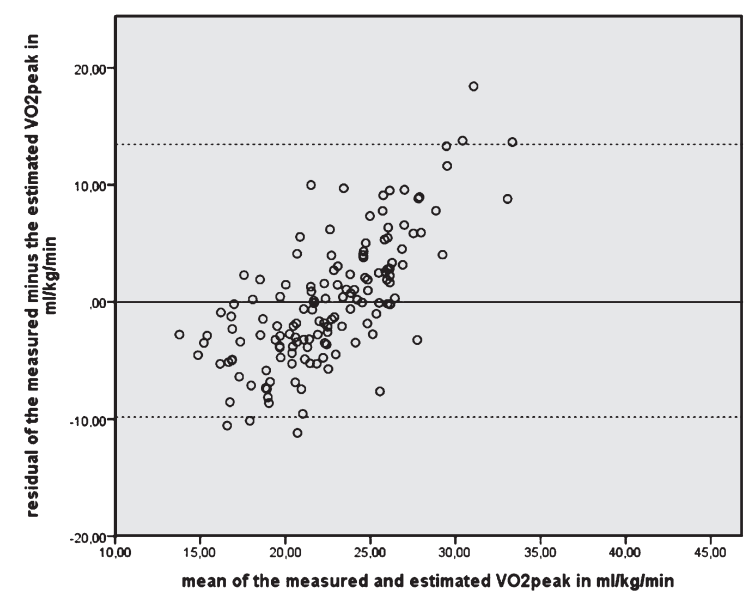

Fig. 3. Bland and Altman plot of agreement between measured VO2peak in $\mathrm{mL} / \mathrm{kg} / \mathrm{min}$ and VO2peak estimated from 2 min walk test distance in meters. The horizontal line at 0 represents perfect agreement.

measured VO2peak - predicted VO2peak (on the $\mathrm{Y}$-axis) is 0.713 , indicating the systematic inaccuracy of the prediction.

The multiple regression analyses revealed age, gender, and EDSS as statistically significant interfering factors in predicting VO2peak, with increased explained variance $\mathrm{R}^{2}$ of $33.2 \%$. The absolute standard error of estimate was reduced to $4.87 \mathrm{~mL} / \mathrm{kg} / \mathrm{min}$. The minor (univariate) contribution of the 2 min walk test was no longer statistically significant (see Table I). 
Table 1

Final multiple regression model for predicting VO2peak ( $\mathrm{mL} / \mathrm{kg} / \mathrm{min})$

\begin{tabular}{lcccr}
\hline Variable & Unstandardized B coefficient & Standard error & Change in $\mathrm{R}^{2}$ & Partial R $^{\text {S }}$ \\
\hline Intercept & 29.334 & 3.892 & & \\
2 min walk test distance (m) & 0.014 & 0.013 & 0.159 & 0.092 \\
Gender (men) & 4.287 & 0.990 & 0.058 & 0.356 \\
Age & -0.144 & 0.047 & 0.074 & -0.263 \\
EDSS & -1.284 & 0.453 & 0.042 & -0.242 \\
\hline
\end{tabular}

*Women as reference.

\section{Discussion}

This study shows that the criterion validity of the 2 min fast walk test as a simple clinical exercise test is insufficient to accurately estimate the aerobic capacity of severely fatigued persons with MS. The walking distance achieved in 2 minutes of fast walking is not a valid predictor of their VO2peak.

\subsection{In context of published literature}

The criterion validity of 2 min walk test in estimating VO2peak was investigated in two other study populations (Leung, Chan, Sykes, \& Chan, 2006; Bernstein, Despars, Singh, Avalos, Stansbury, \& Light, 1994). In 45 elderly Chinese patients experiencing moderate to severe exercise limitations due to COPD, a Pearson correlation of 0.555 was found between the 2 min walk test (mean $130.8 \mathrm{~m}$, sd 28.8) and VO2peak (mean $9.91 \mathrm{~mL} / \mathrm{kg} / \mathrm{min}, \mathrm{sd} 2.63$ ) (Leung et al., 2006). In the same study, the correlation of the 6 min walk test with VO2peak was 0.65 , which led the authors to conclude that the 2 min walk test can assess exercise capacity as accurately as walking tests of longer duration (Leung et al., 2006). A small study in nine elderly men with COPD also reported on the criterion validity of the 2 min walk distance, however, using six 2 min intervals as part of the $12 \mathrm{~min}$ walk test (Bernstein et al., 1994). The correlations with VO2peak were more or less similar for all of the different 2 min intervals $(r=0.66-0.71)$, except for the first 2 minutes in which the largest distance was covered $(r=0.55)$ (Bernstein et al., 1994).

In patients with MS, the prediction of aerobic capacity using other test outcomes, was investigated by Kuspinar and colleagues (Kuspinar, Andersen, Teng, Asano, \& Mayo, 2010). A submaximal step test, grip strength, the 6 min walk test, body weight and sex were strong predictors of exercise capacity in 59 patients with MS (average age 39 years, $66 \%$ women, median EDSS score 1.5, mean VO2max $27.6 \mathrm{~mL} / \mathrm{kg} / \mathrm{min}$ ). VO2max relative to body weight (i.e. expressed in $\mathrm{mL} / \mathrm{kg} / \mathrm{min}$ ), predicted by the step test, the 6 min walk test, and adjusted for sex, explaining $55 \%$ of the variance. Other physical tests did not improve the prediction (Kuspinar et al., 2010).

The VO2max can be more accurately predicted by the linearly related maximum work rate derived from the same incremental exercise test on a cycle ergometer (Motl \& Fernhall, 2012). In 32 women with RRMS (mean VO2max $22.1 \mathrm{~mL} / \mathrm{kg} / \mathrm{min}$, mean age 43.6 years, median self-reported EDSS 1.5) the VO2max prediction equation resulted in an absolute standard error of estimate of $131.3 \mathrm{~mL}$, and an explained variance of $89 \%$. The findings of this study imply for clinical practice that maximum work rate measured during an incremental exercise test without advanced ventilation and gas exchange measurement is suitable for accurate prediction of VO2max (Motl \& Fernhall, 2012).

Most often, walk tests of a longer duration or distance are used as submaximal exercise tests (Mayorga-Vega et al., 2016; Mänttäri, Suni, Sievänen, Husu, Vähä-Ypyä, Valkeinen, Tokola \& Vasankari, 2018). We are not aware of criterion validity studies in patients with MS, in which for instance the distance of the $6 \mathrm{~min}$ walk test as the single predictor fulfils the 0.70 criterion of sufficient criterion validity to predict VO2peak. Nonetheless, the $6 \mathrm{~min}$ walk test is part of the core outcome set as a measure of exercise tolerance in people with MS (Paul et al., 2014). As the distance covered during a 2 min walk test highly correlates with the distance covered during a 6 min walk test (Gijbels, Op 't Eijnde, \& Feys P, 2011; Scalzitti, Harwood, Maring, Leach, Ruckert, \& Costello, 2018; Butland, Pang, Gross, Woodcock, $\&$ Geddes, 1982), it was expected that the 2 min walk would also highly correlate with VO2peak. In our study population, it is assumed that the duration of the 2 min walk test was too short to stress the cardiopulmonary system adequately enough for predicting the VO2peak. A healthy reference population, however, achieved $70 \%$ of their predicted maximum heart rate during the 2 min walk test (Selman, de Camargo, 
Santos, Lanza, \& Dal Corso, 2014). In patients with COPD, the 6 min walk test was more exhausting to perform and correlated stronger with VO2peak, than the 2 min walk test (Leung et al., 2006).

\subsection{Study limitations}

A cycle ergometer was used to measure VO2peak, because this test is generally safer and easier to administer in patients with MS than using a treadmill walking test. Twelve patients $(8.5 \%)$ used a walking aid during the 2 min walk test. In all participants, their walking ability might have hampered their performance on the 2 min walk test. In patients with MS it is worthwhile to investigate the concurrent validity of cardiopulmonary exercise testing on a treadmill and on a cycle ergometer, and the influence of walking difficulties. Data were collected among fatigued MS patients from two different rehabilitation exercise labs with a different assessor, and slightly different equipment. We used a simple 2 min walk test; cardiopulmonary parameters (e.g. heart rate or oxygen consumption during walking) were not measured during the $2 \mathrm{~min}$ walk test. The use of a portable gas analyser and a heart rate monitor would have provided us data about the intensity of 2 minutes of fast walking in fatigued persons with MS (Gjellesvik, Brurok, Tjønna, Tørhaug, \& Askim T, 2017; Morard, Besson, Laroche, Naaïm, Gremeaux, \& Casillas, 2017).

\section{Conclusion}

Due to the poor correlation found between the 2 min walk test and VO2peak, the 2 min walk test cannot be recommended as a valid alternative for estimating aerobic capacity in patients with MS.

\section{Conflict of interest}

The authors declare that there is no conflict of interest.

\section{Funding}

The TREFAMS-ACE Research Programme was financially supported by The Fonds NutsOhra (ZonMw 89000005).

\section{Trial Registrations}

Current Controlled Trials ISRCTN69520623, and ISRCTN58583714.

\section{References}

Balady, G. J., Arena, R., Sietsema, K., Myers, J., Coke, L., Fletcher, G. F., Forman, D., Franklin, B., Guazzi, M., Gulati, M., Keteyian, S. J., Lavie, C. J., Macko, R., Mancini, D., \& Milani, R. V. (2010). American Heart Association Exercise, Cardiac Rehabilitation, and Prevention Committee of the Council on Clinical Cardiology; Council on Epidemiology and Prevention; Council on Peripheral Vascular Disease; \& Interdisciplinary Council on Quality of Care and Outcomes Research. Clinician's Guide to cardiopulmonary exercise testing in adults: A scientific statement from the American Heart Association. Circulation, 122, 191-225.

Bernstein, M. L., Despars, J. A., Singh, N. P., Avalos, K., Stansbury, D. W., \& Light, R. W. (1994). Reanalysis of the 12-minute walk in patients with chronic obstructive pulmonary disease. Chest, 105, 163-167.

Bland, J. M., \& Altman, D. G. Statistical methods for assessing agreement between two methods of clinical measurement. Lancet, 1986(i), 307-310.

Butland, R. J., Pang, J., Gross, E. R., Woodcock, A. A., \& Geddes, D. M. (1982). Two-, six-, and 12-minute walking tests in respiratory disease. Br Med J, 284(6329), 1607-1608.

Cahalin, L. P., Mathier, M. A., Semigran, M. J., Dec, G. W., \& DiSalvo, T. G. (1996). The six-minute walk test predicts peak oxygen uptake and survival in patients with advanced heart failure. Chest, 110, 325-332.

Driehuis, E. R., van den Akker, L. E., de Groot, V., \& Beckerman, H. (2018). Aerobic capacity explains physical functioning and participation in patients with multiple sclerosis-related fatigue. J Rehabil Med, 50, 185-192.

ERS Task Force, Palange, P., Ward, S. A., Carlsen, K. H., Casaburi, R., Gallagher, C. G., Gosselink, R., O’Donnell, D. E., PuenteMaestu, L., Schols, A. M., Singh, S., \& Whipp, B. J. (2007). Recommendations on the use of exercise testing in clinical practice. Eur Respir J, 29, 185-209.

Gijbels, D., Dalgas, U., Romberg, A., de Groot, V., Bethoux, F., Vaney, C., Gebara, B., Medina, C. S., Maamâgi, H., Rasova, K., de Noordhout, B. M., Knuts, K., \& Feys P. (2012). Which walking capacity tests to use in multiple sclerosis? A multicentre study providing the basis for a core set. Mult Scler, 18, 364-371.

Gijbels, D., Op 't Eijnde, B., \& Feys, P. (2011). Comparison of the 2- and 6-minute walk test in multiple sclerosis. Mult Scler, 17, 1269-1272.

Gjellesvik, T. I., Brurok, B., Tjønna, A. E., Tørhaug, T., \& Askim, T. (2017). Oxygen uptake during functional activities after stroke-Reliability and validity of a portable ergospirometry system. PLoS One, 12, e0186894.

Heine, M., van den Akker, L. E., Verschuren, O., Visser-Meily, A., Kwakkel, G.; \& TREFAMS-ACE Study Group. (2015). Reliability and responsiveness of cardiopulmonary exercise testing in fatigued persons with multiple sclerosis and low to mild disability. PLoS One, 10, e0122260. 
Heine, M., Verschuren, O., Hoogervorst, E. L., van Munster, E., Hacking, H. G., Visser-Meily, A., Twisk, J. W., Beckerman, H., de Groot, V., Kwakkel, G.; \& TREFAMS-ACE study group. (2017). Does aerobic training alleviate fatigue and improve societal participation in patients with multiple sclerosis? A randomized controlled trial. Mult Scler, 23, 1517-1526.

Kurtzke, J. F. (1983). Rating neurologic impairment in multiple sclerosis: An expanded disability status scale (EDSS). Neurology, 33, 1444-1452.

Kuspinar, A., Andersen, R. E., Teng, S. Y., Asano, M., \& Mayo, N. E. (2010). Predicting exercise capacity through submaximal fitness tests in persons with multiple sclerosis. Arch Phys Med Rehabil, 91, 1410-1417.

Langeskov-Christensen, M., Heine, M., Kwakkel, G., \& Dalgas, U. (2015). Aerobic capacity in persons with multiple sclerosis: A systematic review and meta-analysis. Sports Med, 45, 905-923.

Leung, A. S., Chan, K. K., Sykes, K., \& Chan, K. S. (2006). Reliability, validity, and responsiveness of a 2-min walk test to assess exercise capacity of COPD patients. Chest, 130, 119-125.

Mandic, S., Walker R., Stevens E., Nye E.R., Body D., Barclay L., \& Williams M. J. (2013). Estimating exercise capacity from walking tests in elderly individuals with stable coronary artery disease. Disabil Rehabil, 35, 1853-1858.

Mänttäri, A., Suni, J., Sievänen, H., Husu, P., Vähä-Ypyä, H., Valkeinen, H., Tokola, K., \& Vasankari, T. (2018). Six-minute walk test: A tool for predicting maximal aerobic power (VO2 max) in healthy adults. Clin Physiol Funct Imaging, 38, 10381045.

Mayorga-Vega, D., Bocanegra-Parrilla, R., Ornelas, M., \& Viciana, J. (2016). Criterion-Related Validity of the Distance- and TimeBased Walk/Run Field Tests for Estimating Cardiorespiratory Fitness: A Systematic Review and Meta-Analysis. PLoS One, 11, e0151671.

Marzolini, S., Oh, P., Corbett, D., Dooks, D., Calouro, M., MacIntosh, B. J., Goodman, R., \& Brooks, D. (2016). Prescribing Aerobic Exercise Intensity without a Cardiopulmonary Exercise Test Post Stroke: Utility of the Six-Minute Walk Test. $J$ Stroke Cerebrovasc Dis, 25, 2222-2231.

Morard, M. D., Besson, D., Laroche, D., Naaïm, A., Gremeaux, V., \& Casillas, J. M. (2017). Fixed-distance walk tests at comfortable and fast speed: Potential tools for the functional assessment of coronary patients? Ann Phys Rehabil Med, 60, 13-19.
Motl, R. W., \& Fernhall, B. (2012). Accurate prediction of cardiorespiratory fitness using cycle ergometry in minimally disabled persons with relapsing-remitting multiple sclerosis. Arch Phys Med Rehabil, 93, 490-495.

Paul, L., Coote, S., Crosbie, J., Dixon, D., Hale, L., Holloway, E., McCrone, P., Miller, L., Saxton, J., Sincock, C., \& White, L. (2014). Core outcome measures for exercise studies in people with multiple sclerosis: Recommendations from a multidisciplinary consensus meeting. Mult Scler, 20, 1641-1650.

Pin, T. W. (2014). Psychometric properties of 2-minute walk test: A systematic review. Arch Phys Med Rehabil, 95, 1759-1775.

Scalzitti, D. A., Harwood, K. J., Maring, J. R., Leach, S. J., Ruckert, E. A., \& Costello, E. (2018). Validation of the 2-Minute Walk Test with the 6-Minute Walk Test and Other Functional Measures in Persons with Multiple Sclerosis. Int J MS Care, 20, 158-163.

Selman, J. P., de Camargo, A. A., Santos, J., Lanza, F. C., \& Dal Corso, S. (2014). Reference equation for the 2-minute walk test in adults and the elderly. Respir Care, 59, 525-530.

Solway, S., Brooks, D., Lacasse Y., \& Thomas, S. (2001). A qualitative systematic overview of the measurement properties of functional walk tests used in the cardiorespiratory domain. Chest, 119, 256-270.

Terwee, C. B., Bot, S. D., de Boer, M. R., van der Windt, D. A., Knol, D. L., Dekker, J., Bouter, L. M., \& de Vet, H. C. (2007). Quality criteria were proposed for measurement properties of health status questionnaires. J Clin Epidemiol, 60, 34-42.

Thompson, W., Gordon, N., \& Pescatello, L. (2010). American College of Sports Medicine: ACSM's guidelines for exercise testing and prescription. 8th edn. Philadelphia: Lippincott Williams \& Wilkins.

Valet, M., Lejeune, T., Hakizimana, J. C., \& Stoquart, G. (2017). Quality of the tools used to assess aerobic capacity in people with multiple sclerosis. Eur J Phys Rehabil Med, 53, 759-774.

van den Akker, L. E., Beckerman, H., Collette, E. H., Twisk, J. W., Bleijenberg, G., Dekker, J., Knoop, H., de Groot V. \& TREFAMS-ACE Study Group. (2017). Cognitive behavioral therapy positively affects fatigue in patients with multiple sclerosis: Results of a randomized controlled trial. Mult Scler, 23, $1542-1553$. 